Kipros Herodotou Nicolaides ${ }^{1}$

LuCIANA de Barros Duarte ${ }^{2}$

AlesSandRa CRISTINA MarColim ${ }^{3}$

Geraldo Duarte ${ }^{4}$

Artigo de Revisão

Palavras-chave

Aberrações cromossômicas

Primeiro trimestre de gravidez Ultra-sonografia

Diagnóstico pre-natal/métodos

Gonadotropina coriônica

Medição da translucência nucal

Proteína plasmática-A associada à gestação

Keywords

Chromosome aberrations

Pregnancy trimester first Ultrasonography

Prenatal diagnosis/methods

Chorionic gonadotropin

Nuchal translucency measurement Pregnancy-associated plasma protein-A

\section{Rastreio para anomalias cromossômicas no primeiro trimestre da gestação}

\author{
First-trimester screening for chromosomal abnormalities
}

\section{Resumo}

Um efetivo rastreio para anomalias cromossômicas pode ser realizado no primeiro trimestre da gestação. A associação entre a transluscência nucal (TN) e as concentrações séricas maternas da fração $\beta$-livre da gonadotrofina coriônica humana e da proteína plasmática-A associada à gestação pode identificar $90 \%$ dos fetos com trissomia do cromossomo 21 e outras anomalias cromossômicas, com uma taxa de falso-positivo de 5\%. Esses números são superiores aos obtidos pelo rastreio utilizando-se apenas a idade materna (30\%) ou o rastreio bioquímico materno, no segundo trimestre da gestação (65\%). Um rastreio mais eficaz, no primeiro trimestre, pode ser atingido por meio de uma avaliação ecográfica em dois tempos, dividindo-se as pacientes em grupos de alto, intermediário e baixo risco. No grupo de alto risco, o diagnóstico invasivo estaria indicado, ao contrário do grupo de baixo risco, no qual a presença de uma anomalia seria pouco provável. No grupo de risco intermediário (risco de 1 em 101 a 1 em 1.000), seria oferecida uma segunda avaliação ecográfica, para posicionar a paciente no grupo de alto ou baixo risco (presença/ausência do osso nasal ou presença/ausência da regurgitação tricúspide ou presença/ausência de alteração do fluxo sangüíneo no ducto venoso). A biópsia de vilo corial estaria indicada quando, após a realização da segunda abordagem, o risco ajustado da paciente se tornasse maior ou igual a 1 em 100. Essa segunda abordagem ecográfica deveria ser realizada por pessoal treinado, e os seus resultados deveriam ser constantemente avaliados, como um controle de qualidade. Esse processo foi estabelecido pela Fetal Medicine Foudation e aceito internacionalmente.

\section{Abstract}

Screening for major chromosomal abnormalities can be provided in the first trimester of pregnancy. Screening by a combination of fetal nuchal translucency and maternal serum free human chorionic gonadotropin and pregnancyassociated plasma protein-A can identify $90 \%$ of fetuses with trisomy 21 and other major chromosomal abnormalities for a false-positive rate of $5 \%$. This is superior to the $30 \%$ detection rate achieved by maternal age and $65 \%$ by second-trimester maternal serum biochemistry. A further improvement in the effectiveness of first-trimester screening is likely to be achieved by a risk-orientated two-stage approach. In this approach, the patients are subdivided into a high-risk group, requiring invasive testing; a low-risk group, which can be reassured that an abnormality is unlikely, and an intermediate-risk group (risk of 1 in 101 to 1 in 1000), in which further assessment is performed by first-trimester ultrasound examination (for presence/absence of the nasal bone or presence/absence of tricuspid regurgitation or normal/abnormal Doppler velocity waveform in the ductus venosus), and chorionic villus sampling is performed if their adjusted risk becomes 1 in 100 or more. Those performing first-trimester scans should be appropriately trained and their results subjected to external quality assurance. This process was well established by the Fetal Medical Foundation several years ago and is widely accepted internationally.
Trabalho realizado no Harris Birthright Research. Center for Fetal Medicine, King's College, London University - London, UK. Professor em Medicina Fetal, Médico Especialista em Obstetrícia, Diretor do Harris Birthright Research Center para Medicina Fetal, King's College Hospital Medical School - London, UK.

2 Research Fellow no Harris Birthright Research Center, for Fetal Medicine, King's College, London University; Pós-graduanda Níve Doutorado do Departamento de Ginecologia e Obstetrícia da Faculdade de Medicina de Ribeirão Preto da Universidade de São Paulo - USP - Ribeirão Preto (SP), Brasil.

${ }^{3}$ Médica Assistente do Hospital das Clínicas da Faculdade de Medicina de Ribeirão Preto; Pós-graduanda Nível Doutorado do Departamento de Ginecologia e Obstetrícia da Faculdade de Medicina de Ribeirão Preto da Universidade de São Paulo - USP Ribeirão Preto (SP), Brasil.

4 Professor Titular do Departamento de Ginecologia e Obstetrícia da Faculdade de Medicina de Ribeirão Preto da Universidade de São Paulo - USP - Ribeirão Preto (SP), Brasil. 


\section{Introdução}

O diagnóstico pré-natal das anomalias cromossômicas é possível com a utilização de testes invasivos como a biópsia de vilo corial, a partir da $11^{\mathrm{a}}$ semana, ou a amniocentese, a partir da $16^{\mathrm{a}}$ semana. Entretanto, visto que o risco relativo de aborto com estas intervenções diagnósticas é cerca de $1 \%{ }^{1}$, tanto para as pacientes submetidas à biópsia de vilo corial quanto para as pacientes submetidas à amniocentese, o diagnóstico invasivo fica reservado apenas para as pacientes com elevado risco de que o feto seja portador de cromossomopatia.

O tradicional método de rastreio para as anomalias cromossômicas é a idade materna. Utilizando-a como método de rastreio, cerca de $5 \%$ da população deverá ser submetida a um diagnóstico invasivo para confirmação do cariótipo, identificando aproximadamente $30 \%$ dos fetos portadores da trissomia do 21. Por outro lado, sabe-se que a combinação entre idade materna, ecografia e rastreio dos marcadores bioquímicos séricos maternos, realizada entre a $11^{\underline{a}}$ e a $13^{\underline{a}}$ semana de gestação, identifica $90 \%$ dos fetos portadores da trissomia do 21 e de outros defeitos cromossômicos maiores, sendo necessário submeter, portanto, menos de 3\% da população a diagnósticos invasivos ${ }^{2}$.

Com o avanço da idade materna, aumenta também o risco do feto de ser portador de uma anomalia cromossômica. Os fetos portadores de anomalias cromossômicas apresentam um risco maior de óbito intra-útero espontâneo do que os fetos cromossomicamente normais ${ }^{3-5}$. Dessa forma, o risco de uma paciente estar grávida de um feto portador de uma anomalia cromossômica diminui com o avanço da idade gestacional (Tabela 1$)^{3-5}$.
Na trissomia do cromossomo 21, os índices de morte fetal entre a $12^{\mathrm{a}}$ e a $40^{\mathrm{a}}$ semana estão em torno de $30 \%$. Nas trissomias do 18 e 13, os índices de morte fetal entre a $12^{\mathrm{a}}$ e a $40^{\mathrm{a}}$ semana de gestação podem chegar a $80 \%{ }^{4}$.

A concepção de embriões com constituição cromossômica $45 \mathrm{X}$ é mais rara do que a concepção de embriões portadores de trissomias, e sua ocorrência não está relacionada com a idade materna. A prevalência está em torno de $1 / 1.500$ na $12^{a}$ semana gestacional e em $1 / 4.000$ na $40^{\underline{a}}$ semana da gravidez. A poliploidia afeta cerca de $2 \%$ das gestações, entretanto, é altamente letal e de ocorrência extremamente rara em nascidos vivos. A sua prevalência é de $1 / 2.000$ na $12^{\mathrm{a}}$ semana e de 1 em 250.000 no termo da gravidez .

$\mathrm{O}$ risco individual de cada gestante de ter um feto portador de uma anomalia cromossômica pode ser calculado, mas para isso é necessário levar em consideração o seu risco basal (inicial), o qual depende da idade materna, da idade gestacional e da história prévia de anomalias cromossômicas ${ }^{2}$. Após esta determinação inicial, este risco basal deve ser multiplicado por uma série de fatores de correção, que dependem do resultado dos diferentes testes de rastreamento realizados durante a gravidez. Toda vez que um teste de rastreamento é realizado, o risco basal é multiplicado pelo fator de correção desse teste e um novo risco é obtido. Esse então passa a ser o risco basal para o próximo teste ${ }^{2}$.

\section{Marcadores séricos bioquímicos maternos}

Em gestações de fetos com a trissomia do cromossomo 21 , as concentrações de determinados hormônios produzidos pela placenta encontram-

Tabela 1 - Risco estimado para trissomias do 21,18 e 13 (Risco=l/ número apresentado na tabela) em relação à idade materna ${ }^{3.5}$.

\begin{tabular}{|c|c|c|c|c|c|c|c|c|c|}
\hline \multirow{3}{*}{ Idade materna (anos) } & \multicolumn{3}{|c|}{ Trissomia 21} & \multicolumn{3}{|c|}{ Trissomia 18} & \multicolumn{3}{|c|}{ Trissomia 13} \\
\hline & \multicolumn{3}{|c|}{ Idade gestacional (semanas) } & \multicolumn{3}{|c|}{ Idade gestacional (semanas) } & \multicolumn{3}{|c|}{ Idade gestacional (semanas) } \\
\hline & 12 & 20 & 40 & 12 & 20 & 40 & 12 & 20 & 40 \\
\hline 20 & 1068 & 1295 & 1527 & 2484 & 4897 & 18013 & 7826 & 14656 & 42423 \\
\hline 25 & 946 & 1147 & 1352 & 2200 & 4336 & 15951 & 6930 & 12978 & 37567 \\
\hline 30 & 626 & 759 & 895 & 1456 & 2869 & 10554 & 4585 & 8587 & 24856 \\
\hline 31 & 543 & 658 & 776 & 1263 & 2490 & 9160 & 3980 & 7453 & 21573 \\
\hline 33 & 383 & 464 & 547 & 891 & 1755 & 6458 & 2806 & 5254 & 15209 \\
\hline 34 & 312 & 378 & 446 & 725 & 1429 & 5256 & 2284 & 4277 & 12380 \\
\hline 35 & 249 & 302 & 356 & 580 & 1142 & 4202 & 1826 & 3419 & 9876 \\
\hline 36 & 196 & 238 & 280 & 456 & 899 & 3307 & 1437 & 2691 & 7788 \\
\hline 37 & 152 & 185 & 218 & 354 & 698 & 2569 & 1116 & 2090 & 6050 \\
\hline 38 & 117 & 142 & 167 & 272 & 537 & 1974 & 858 & 1606 & 4650 \\
\hline 40 & 68 & 82 & 97 & 157 & 310 & 1139 & 495 & 927 & 2683 \\
\hline 41 & 51 & 62 & 73 & 118 & 233 & 858 & 373 & 698 & 2020 \\
\hline 42 & 38 & 46 & 55 & 89 & 175 & 644 & 280 & 524 & 1516 \\
\hline
\end{tabular}


se alteradas em relação às gestações normais ${ }^{6,7}$. Estudos realizados, utilizando as concentrações séricas maternas dos marcadores bioquímicos como método de rastreio no primeiro trimestre para anomalias cromossômicas, demonstraram que, entre a $10^{\underline{a}}$ semana e três dias e a $13^{\underline{a}}$ semana e seis dias de gravidez, as dosagens das concentrações séricas maternas da fração $\beta$-livre da gonadotrofina coriônica humana ( $f \beta-h C G$ ) encontram-se mais elevadas, quando comparadas a gestações de fetos cromossomicamente normais. Por outro lado, as concentrações séricas da proteína plasmática-A associada à gestação (PAPP-A) encontram-se diminuídas

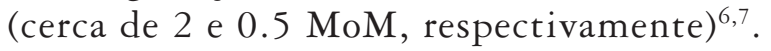

O índice de detecção para trissomia do 21, utilizando-se como método de rastreio a combinação entre idade materna e o rastreio bioquímico ( $\mathrm{f} \beta$-hCG livre e PAPP-A), está em torno de $60 \%$. Por outro lado, quando combinados à idade materna, ao rastreio bioquímico e à transluscência nucal (TN), os índices de detecção passam para $90 \%$, com uma taxa de falso-positivo de $5 \%{ }^{6,7}$. Vale a pena ressaltar que, como método de rastreio, essas dosagens devem ser realizadas entre a $10^{a}$ semana e três dias e a $13^{\underline{a}}$ semana e seis dias de gravidez ${ }^{6,7}$. Entretanto, para que se possam combinar os dois métodos, TN e rastreio dos marcadores bioquímicos, é necessário que as dosagens sejam realizadas ao mesmo tempo em que se realiza a avaliação ecográfica da $\mathrm{TN}^{6,7}$.

Não existe correlação significativa entre os marcadores ecográficos e as concentrações séricas maternas da $\mathrm{f} \beta$-hCG livre e da PAPP-A, tanto nos fetos portadores da trissomia do 21 quanto nos fetos cromossomicamente normais. Em outras palavras, não existe relação entre a espessura da TN e as concentrações maiores ou menores desses marcadores. Entretanto, quando usados em conjunto, os marcadores ecográficos e bioquímicos representam métodos de rastreio mais eficazes do que quando utilizados individualmente.

Nas trissomias do 18 e 13 , tanto as concentrações séricas da $\mathrm{f} \beta$-hCG livre quanto as da PAPP-A encontram-se diminuídas (cerca de $3 \mathrm{MoM})^{8,9}$. Nas trissomias dos cromossomos sexuais, as concentrações séricas da f $\beta$-hCG livre estão normais e as da PAPP-A encontram-se diminuídas (cerca de $0,5 \mathrm{MoM})^{10}$. $\mathrm{Na}$ triploidia de origem paterna (diândrica), as concentrações séricas da f $\beta$-hCG livre estão significantemente aumentadas (10 MoM) e as da PAPP-A encontram-se moderadamente diminuídas. Por sua vez, na triploidia de origem materna (digínica), as concentrações séricas da $\mathrm{f} \beta$-hCG livre, assim como as concentrações da PAPP-A, encontram-se claramente reduzidas (menos que $0,1 \mathrm{MoM})^{11}$.

\section{Marcadores ultra-sonográficos no primeiro trimestre}

\section{Transluscência nucal}

Estudos realizados nos últimos 15 anos estabeleceram que a medida da espessura da TN é um método de rastreio efetivo e precoce das anomalias cromossômicas ${ }^{12-14}$. Além disso, a TN aumentada está associada a defeitos cardíacos e a um largo espectro de outras malformações e síndromes genéticas ${ }^{15-17}$.

A TN fetal pode ser medida tanto por via abdominal quanto por via transvaginal, obtendo-se resultados similares. A idade gestacional ideal para medida da TN é entre a $11^{\underline{a}}$ e a $13^{\underline{a}}$ semana e seis dias de gravidez. O comprimento crânio-nádega mínimo deverá estar entre 45 e $84 \mathrm{~mm}$. O limite mínimo foi escolhido para permitir o diagnóstico da maioria das anomalias fetais que, de outra forma, não seriam detectadas ${ }^{2}$.

A magnificação da imagem deve ser a maior possível, incluindo na imagem apenas a cabeça fetal e a parte superior do tórax fetal. A obtenção de corte sagital médio do feto em posição neutra de boa qualidade é fundamental para uma boa avaliação. A espessura máxima do espaço anecóico (transluscência) entre a pele e o tecido celular subcutâneo que recobre a coluna cervical deve ser medida (Figura 1).

Durante a realização do exame, mais de uma medida deve ser realizada, considerando-se a maior delas para o cálculo do risco. A TN aumenta com o crescimento do comprimento crânio-nádega, tornando-se essencial levar em consideração a idade gestacional ao se definir se a TN está aumentada ou não. O percentil 95 th da TN, quando o comprimento crânio-nádega é 45 e 84 mm, é, respectivamente, 2,1 e $2,7 \mathrm{~mm}^{13}$.

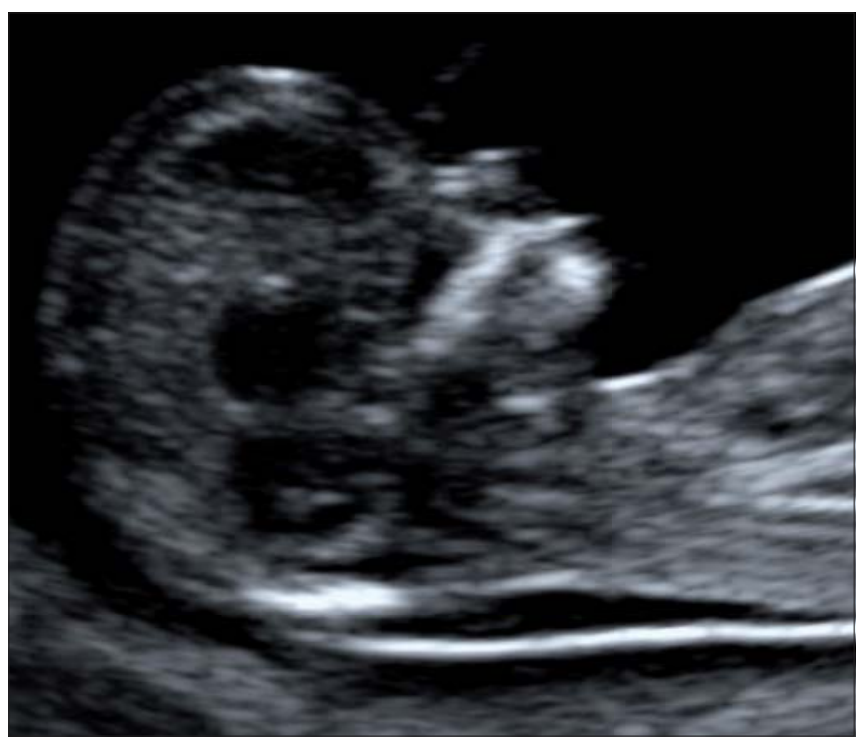

Figura 1 - Imagem adequada para medida da transluscência nucal. 
Vários estudos prospectivos avaliando mais de 250.000 gestações, incluindo aproximadamente 1.000 fetos com trissomia do 21, demonstraram que a TN é medida com sucesso em mais de $99 \%$ dos casos ${ }^{2}$. Observou-se também que o risco das anomalias cromossômicas cresce com o avançar da idade materna e com o aumento da espessura da $\mathrm{TN}^{14,18}$. A TN, quando utilizada como método de rastreio para anomalias cromossômicas, identifica de 75 a $80 \%$ dos fetos com trissomia do 21 e outras cromossomopatias maiores, com uma taxa de falso-positivo de 5\%.

\section{Osso nasal ausente ou hipoplásico}

Foi Langdon Down $(1866)^{19}$ quem primeiro descreveu os achados em pacientes com síndrome de Down. Este autor notou que a face plana e o nariz de pequenas dimensões eram características comuns aos pacientes portadores dessa síndrome. Durante a realização do exame ecográfico da $11^{\mathrm{a}}$ a $13^{\mathrm{a}}$ semana e seis dias de gestação, o osso nasal pode não ser visualizado devido a uma hipoplasia ou atraso na calcificação. Isso ocorre em 2 a $3 \%$ dos fetos cromossomicamente normais e em 60 a $70 \%$ dos fetos com trissomia do $21^{20-22}$. A prevalência da ausência do osso nasal é maior em fetos de origem afro-caribenha do que em fetos de origem caucasiana e maior em fetos com o aumento da espessura da $\mathrm{TC}^{20-22}$.

Para a avaliação ecográfica do osso nasal, a imagem deve ser magnificada de forma que apenas a cabeça e o tórax fetal sejam incluídos na tela, obtendo-se um corte sagital médio do perfil fetal. O transdutor ecográfico deverá ficar paralelo ao sentido do nariz fetal e angulado levemente de um lado ao outro do nariz fetal. Quando esse critério for satisfeito, três linhas distintas serão visualizadas na altura do nariz fetal. As primeiras duas linhas, próximas à fronte fetal, são horizontais e paralelas uma a outra. A linha superior representa a pele e a inferior (geralmente mais fina e mais ecogênica do que a pele que a recobre) representa o osso nasal. A terceira linha, quase em continuidade com a pele apenas um pouco superior a essa, representa a ponta do nariz.

A ausência/presença do osso nasal ocorre de forma independente das alterações nas concentrações séricas maternas da $\mathrm{f} \beta$-hCG livre e da PAPP-A. Entretanto, a ausência do osso nasal associada à alteração nas concentrações dos marcadores bioquímicos maternos aumenta o risco para anomalias cromossômicas.

Adicionalmente, quando o rastreio é realizado pela combinação da idade materna, espessura da TN, concentrações séricas maternas da f $\beta$-hCG livre e da PAPP-A e presença/ausência osso nasal pode detectar cerca de $90 \%$ dos fetos portadores da trissomia do 21 com uma simultânea redução dos índices falsos-positivos de 5 para 2,5\% ${ }^{22}$.

\section{Regurgitação da tricúspide fetal}

Sabe-se que a TN aumentada, no primeiro trimestre gestacional, está associada à presença de anomalias cromossômicas e malformações cardíacas ${ }^{12-17}$. A associação com defeitos cardíacos fez com que a avaliação do coração de fetos com TN aumentada fosse realizada mais precocemente em centros especializados. Nessa avaliação precoce, foi observada uma estreita associação entre a regurgitação da tricúspide (mesmo na ausência de outros achados cardíacos anormais) e o aumento na prevalência de defeitos cromossômicos ${ }^{23}$. Os estudos realizados sobre este tema demonstraram que a ecografia realizada entre a $11^{\underline{a}}$ e a $13^{\underline{a}}$ semana e seis dias de gestação diagnosticou a regurgitação da tricúspide em 2 a $3 \%$ dos fetos cromossomicamente normais e em 60 a $70 \%$ dos fetos com trissomia do 21. Esses estudos também determinaram que a prevalência da regurgitação da tricúspide cresce com o aumento da espessura da TN e na presença de outros defeitos cardíacos, mas diminui com o avanço da gravidez ${ }^{23,24}$.

Para avaliação do fluxo tricúspide, a imagem deve ser magnificada de forma que só o tórax esteja incluído na tela. A presença ou ausência da regurgitação da tricúspide é determinada pelo Doppler pulsado. A amostra de volume é posicionada verticalmente, compreendendo todos os folhetos da válvula tricúspide, devendo o ângulo de direção do fluxo ser menor que $30^{\circ}$. A regurgitação da tricúspide, no primeiro trimestre, é diagnosticada quando estiver presente em pelo menos metade da sístole e com velocidade maior que $80 \mathrm{~cm} / \mathrm{s}$.

Não existe associação significativa entre a presença da regurgitação da tricúspide e alterações nas concentrações séricas maternas da $\mathrm{f} \beta$-hCG livre e da PAPP$\mathrm{A}^{23,24}$. Porém, de forma semelhante à avaliação do osso nasal, o rastreio combinando idade materna, avaliação da TN, concentrações séricas maternas da f $\beta$-hCG livre e da PAPP-A e presença/ausência da regurgitação da tricúspide detecta $90 \%$ dos fetos portadores da trissomia do 21 , com uma simultânea redução da taxa de falso-positivo de $5 \%$ para $2,5 \%{ }^{24}$.

Um benefício adicional em incorporar a avaliação da regurgitação da tricúspide no rastreio de rotina para anomalias cromossômicas, no primeiro trimestre, seria a otimização para o diagnóstico precoce das malformações cardíacas, visto que, para a correta realização do exame, é necessária a adequada visualização das quatro câmaras cardíacas. A própria regurgitação da tricúspide alertaria para possível defeito cardíaco ${ }^{24}$. 


\section{Fluxo venoso anormal no ducto venoso}

O ducto venoso é o único shunt que direciona sangue oxigenado da veia umbilical para a circulação coronária e cerebral, dirigindo o fluxo de sangue oxigenado preferencial pelo forâmen oval do átrio direito para o átrio esquerdo. O fluxo sangüíneo no ducto venoso apresenta onda característica de alta velocidade durante a sístole (onda-S) e a diástole ventriculares (onda-D), e contínuo durante a contração atrial (onda-a). $\mathrm{O}$ aumento da impedância do fluxo sangüíneo no ducto venoso, entre $11^{\underline{a}}$ e $13^{\underline{a}}$ semanas e seis dias de gestação, é manifestado pela ausência ou onda-a reversa. A onda-a ausente ou reversa é observada em 3 a $5 \%$ dos fetos normais e em cerca de $70 \%$ dos fetos com trissomia do $21^{25-27}$.

Para a avaliação do fluxo sangüíneo no ducto venoso, a magnificação da imagem deverá ser suficiente para que apenas o tórax e o abdome fetal ocupem totalmente a tela ${ }^{28}$. O exame deverá ser realizado preferencialmente quando o feto estiver imóvel. Prefere-se um corte sagital ventral médio do tórax fetal, obtendo-se mapeamento com o Doppler colorido, com o objetivo de localizar a veia umbilical, o ducto venoso e o coração fetal. A amostra do Doppler pulsado deve ser pequena $(0,5$ a $1 \mathrm{~mm})$, para evitar a contaminação pelas veias adjacentes, e deve ser colocada na área clara o aliasing (que representa a porção imediatamente acima do sinus umbilical). $\mathrm{O}$ ângulo de insonação deverá ser menor que $30^{\circ}$, e o filtro deverá ser colocado em uma baixa freqüência $(50$ a $60 \mathrm{~Hz}$ ), evitando prejuízos na visibilização da onda. A velocidade deverá ser alta $(2 \mathrm{a} 3 \mathrm{~cm} / \mathrm{s})$, possibilitando que as ondas sejam mais bem distribuídas no traçado, permitindo melhor avaliação da onda-a.

Alterações no estudo Doppler no fluxo sangüíneo do ducto venoso chamaria a atenção para um exame mais detalhado dos outros marcadores ecográficos ${ }^{25-27}$. Estudos preliminares sugerem que o acesso ao ducto venoso em gestações consideradas de alto risco para defeitos cromossômicos pode resultar em maior redução da necessidade da realização de testes invasivos, com um pequeno decréscimo na sensibilidade ${ }^{25-27}$. A realização de testes invasivos, como já foi dito anteriormente, cursa com o risco de $1 \%$ de perda fetal ${ }^{1}$.

\section{Ângulo frontomaxilofacial}

O perfil plano é uma das características dos fetos portadores da trissomia do 21, como já mencionado. Essa característica decorre da hipoplasia maxilar e nasal presentes em fetos portadores dessa síndrome. Estudo ecográfico realizado em fetos entre a $11^{\mathrm{a}}$ e a $13^{\mathrm{a}}$ semana e seis dias de gestação demonstrou que o comprimento maxilar em fetos portadores da trissomia do 21 é mais curto do que o de fetos cromossomicamente normais. Entretanto, a diferença entre as medidas encontradas era de pequena monta para serem clinicamente úteis ${ }^{29}$. Um novo método, denominado ângulo frontomaxilofacial (FMF), avalia de forma mais objetiva a face plana fetal ${ }^{30-32}$.

O ângulo FMF facial é definido como o ângulo entre a superfície cranial da maxila e o osso frontal durante a aquisição do perfil fetal no plano sagital médio. A ecografia tridimensional demonstrou que os marcadores ecográficos que definem um corte sagital médio preciso da face fetal são a fronte, a ponta ecogênica do nariz, a forma retangular do palato e, na parte posterior, o diencéfalo transluscente e a membrana nucal ${ }^{31,32}$. A rotação da cabeça fetal, para fora da posição vertical do eixo do diâmetro occipitofrontal, resulta na não visibilização da ponta do nariz. Geralmente, sobre o mesmo ângulo, a cerca de $10^{\circ}$ do processo zigomático do osso maxilar, é vista a parte anterior do complexo palatomaxilar (Figura 2).
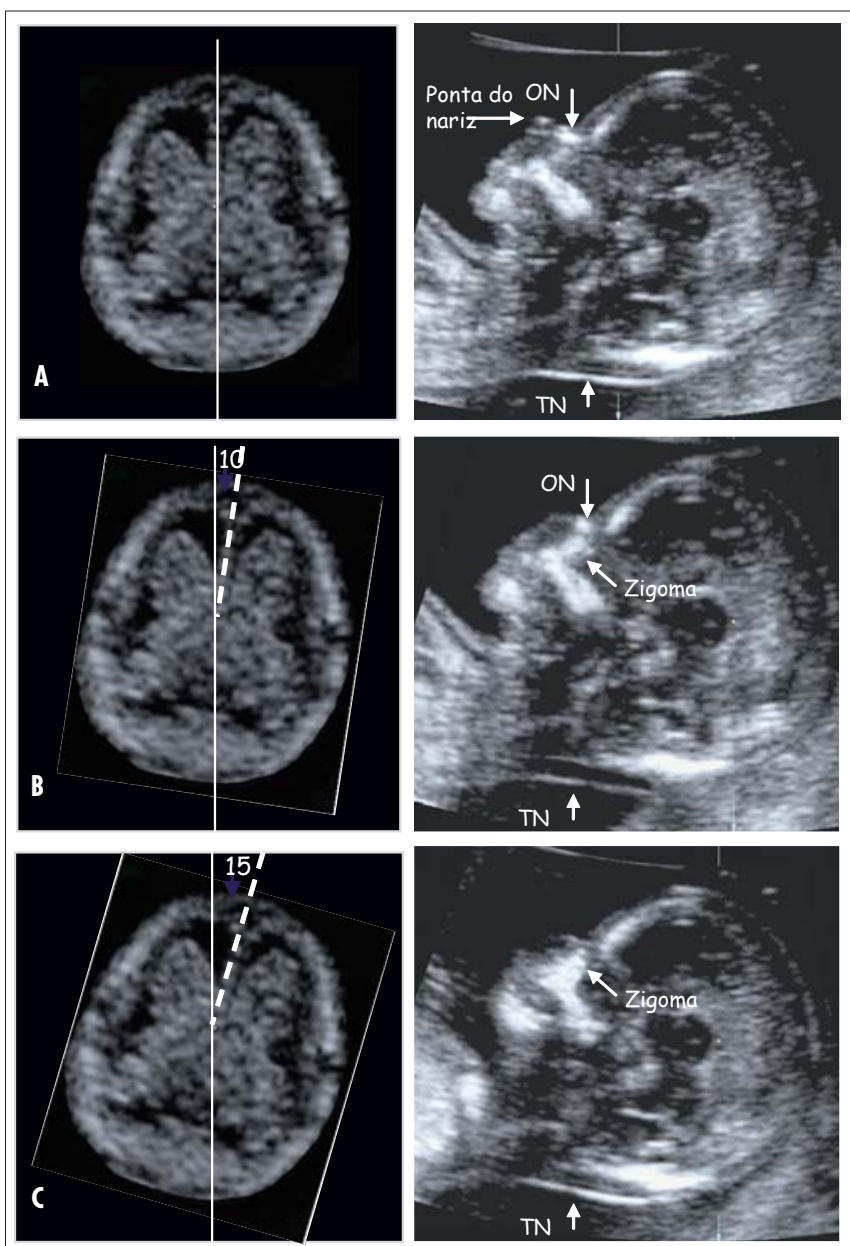

Figura 2 - Imagens ecográficas simultaneamente demonstrando o plano transverso e o correspondente plano sagital da cabeça fetal no plano sagital médio $(A)$, após a rotação, fugindo da linha média do diâmetro biparietal e occiptofrontal até que a ponta do nariz não seja mais vista, e a forma retangular da maxila seja alterada pela superposição do processo zigomático da maxila (B) OS, osso nasal; TN, transluscência nucal (C)32. 
Para a aquisição do ângulo FMF, deve-se traçar uma linha sobre a superfície cranial da maxila e uma linha que atravessa a extremidade posterior distal da maxila e se estende até a superfície externa da fronte. No ponto de interseção entre as duas linhas, o ângulo é avaliado.

Em mais de $60 \%$ dos fetos portadores da trissomia

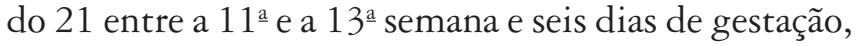
o ângulo FMF encontra-se acima do percentil 95 dos limites normais. $\mathrm{O}$ aumento do ângulo FMF parece ser decorrente da posição da maxila em relação à fronte. Não existe associação significativa entre a presença do ângulo FMF aumentado e alterações nos outros marcadores, como o aumento da espessura da TN, a presença/ ausência do osso nasal ou alterações nas concentrações maternas séricas da fß-hCG livre ou PAPP-A. Por outro lado, quando o ângulo FMF encontra-se aumentado e são observadas alterações nos marcadores ecográficos para aneuploidias fetais no primeiro trimestre, o risco é aumentado para trisomia do $21^{30-32}$.

Embora a medida do ângulo FMF tenha apenas sido realizada por meio da ecografia tridimensional, ela também pode ser realizada pela ecografia bidimensional. Entretanto, é necessário treinamento específico dos operadores, de forma que os mesmos possam reconhecer os marcadores ecográficos que definem o plano sagital médio da face fetal.

\section{Conduta no rastreio do primeiro trimestre}

O rastreio efetivo da trissomia do 21 e dos defeitos cromossômicos maiores pode ser realizado entre a $11^{\underline{a}}$ e a $13^{\underline{a}}$ semana e seis dias de gestação, combinando idade materna, espessura da TN e as concentrações séricas maternas da fß-hCG livre e PAPP-A. Com essa associação, cerca de $5 \%$ da população necessitará de um diagnóstico invasivo e $90 \%$ dos fetos portadores da trissomia do 21 serão identificados ${ }^{2}$.

O objetivo do rastreio dos defeitos cromossômicos no primeiro trimestre da gestação é identificar os fetos de alto risco para essas anomalias, realizando o diagnóstico invasivo principalmente nesse grupo. Entretanto, após a realização do rastreio, um grande número de pacientes classifica-se no grupo de risco intermediário, no qual há a dúvida em realizar ou não o diagnóstico invasivo. Ressalte-se que, de cada cem pacientes que realizam um diagnóstico invasivo (biópsia de vilo corial/amniocentese) uma paciente irá abortar o feto ${ }^{2}$. À luz dessa problemática uma nova abordagem a esse rastreio foi proposta. Para a paciente que se encontre localizada no grupo de risco intermediário, foi proposto o exame adicional, utilizandose os novos marcadores ecográficos como o osso nasal, o ângulo FMF, a regurgitação da tricúspide e o fluxo no ducto venoso. Com essa ampliada avaliação, os índices de detecção podem ultrapassar os $95 \%$. Alternativamente, os índices de detecção podem ser de $90 \%$, com a redução pela metade da taxa de falso-positivo $(2,5 \%)$ do número de testes invasivos ${ }^{18}$.

Preferencialmente, os profissionais que realizam ecografia entre a $11^{\underline{a}}$ e a $13^{\underline{a}}$ semana e seis dias de gestação deveriam ser treinados para avaliar o osso nasal, o ângulo FMF, a regurgitação da tricúspide e o fluxo no ducto venoso, em adição à medida da TN. Entretanto, visto que o tempo de treinamento necessário para se tornar competente na avaliação desses novos marcadores é maior do que o tempo de treinamento para realização do rastreio utilizando a TN, a proposição é de um manejo em dois estágios.

A primeira fase do rastreio envolveria a avaliação da TN e das concentrações séricas maternas da fß-hCG e PAPP-A . As pacientes seriam divididas em três grupos, de acordo com os resultados desse rastreio no primeiro trimestre: grupo de alto risco (risco de 1:100 ou maior), grupo de risco intermediário (1:101$1.000)$ e grupo de baixo risco $(1: 1.001 \text { ou menos })^{18}$. O rastreio realizado no primeiro trimestre irá definir o risco individual de cada paciente em estar grávida de um feto portador de anomalia cromossômica baseado no cálculo do risco baseado na idade materna, TN e nas concentrações séricas dos marcadores bioquímicos maternos $\mathrm{fB}$-hCG e PAPP-A ${ }^{18}$.

Para o grupo de alto risco, é oferecida a biópsia de vilo corial no primeiro trimestre e, para o grupo de baixo risco, a reavaliação do risco por meio da ecografia no segundo trimestre. Ao grupo intermediário, é oferecida uma ecografia mais especializada, na qual se avaliam o osso nasal, o ângulo FMF, a regurgitação da tricúspide e o fluxo sangüíneo no ducto venoso. Caso um desses parâmetros encontre-se alterado, é oferecido à gestante o diagnóstico invasivo no primeiro trimestre. Caso eles se encontrem dentro dos limites da normalidade, a paciente é encaminhada para o grupo de baixo risco ${ }^{18}$.

\section{Agradecimentos}

À Coordenação de Aperfeiçoamento de Pessoal de Nível Superior (Capes), pelo apoio financeiro durante a realização do Programa de Doutorado no país, com estágio no exterior. À Fetal Medicine Foudation, pelo apoio institucional. 
Referências

1. Alfirevic Z, Sundberg K, Brigham S. Amniocentesis and chorionic villus sampling for prenatal diagnosis. Cochrane Database Syst Rev. 2003;(3):CD003252.

2. Nicolaides $\mathrm{KH}$. First-trimester screening for chromosomal abnormalities. Semin Perinatol. 2005;29(4): 190-4.

3. Snijders RJM, Sundberg K, Holzgreve W, Henry G, Nicolaides $\mathrm{KH}$. Maternal age and gestation- specific risk for trisomy 21 . Ultrasound Obstet Gynecol. 1999;13(3):167-70.

4. Snijders R, Holzgreve W, Cuckle H, Nicolaides KH. Maternal age-specific risks for trisomies at 9-14 weeks' gestation. Prenat Diagn. 1994;14(7):543-52.

5. Snijders RJ, Sebire NJ, Nicolaides KH. Maternal age and gestational age-specific risks for chromosomal defects. Fetal Diagn Ther. 1995; 10(6):356-67.

6. Spencer K, Souter V, Tul N, Snijders R, Nicolaides KH. A screening program for trisomy 21 at 10-14 weeks using fetal nuchal translucency, maternal serum free beta-human chorionic gonadotropin and pregnancy-associated plasma protein-A. Ultrasound Obstet Gynecol. 1999; 13(4):231-7.

7. Avgidou K, Papageorghiou A, Bindra R, Spencer K, Nicolaides $\mathrm{KH}$. Prospective first-trimester screening for trisomy 21 in 30,564 pregnancies. Am J Obstet Gynecol. 2005; 192(6):1761-7.

8. Tul N, Spencer K, Noble P, Chan C, Nicolaides KH. Screening for trisomy 18 by fetal nuchal translucency and maternal serum free beta hCG and PAPP-A at 10-14 weeks of gestation. Prenat Diagn. 1999;19(1 1):1035-42.

9. Spencer K, Ong C, Skentou H, Liao AW, Nicolaides KH. Screening for trisomy 13 by fetal nuchal translucency and maternal serum free beta hCG and PAPP-A at 10-14 weeks of gestation. Prenat Diagn. 2000;20(5):411-6.

10. Spencer K, Tul N, Nicolaides KH. Maternal serum free beta-hCG and PAPP-A in fetal sex chromosome defects in the first trimester. Prenat Diagn. 2000;20(5):390-4.

11. Spencer K, Liao AW, Skentou H, Cicero S, Nicolaides KH. Screening for Triploidy by fetal nuchal translucency and maternal serum free B-hCG and PAPP-A at 10-14 weeks of gestation. Prenat Diagn. 2000;20(6):495-9.

12. . Nicolaides KH, Azar G, Byrne D, Mansur C, Marks K. Fetal nuchal translucency: ultrasound screening for chromosomal defects in first trimester of pregnancy. BM. 1992;304(6831):867-9

13. Snijders R, Noble P, Sebire N, Souka A, Nicolaides KH. UK multicentre project on assessment of risk of trisomy 21 by maternal age and fetal nuchal-translucency thickness at 10-14 weeks of gestation. Fetal Medicine Foundation First Trimester Screening Group. Lancet. 1998;352(9125):343-6.

14. Nicolaides KH. Nuchal translucency and other first-trimester sonographic markers of chromosomal abnormalities. Am J Obstet Gynecol. 2004;191(1):45-67.

15. Hyett J, Moscoso G, Papapanagiotou G, Perdu M, Nicolaides KH. Abnormalities of the heart and great arteries in chromosomally normal fetuses with increased nuchal translucency thickness at 11-13 weeks of gestation. Ultrasound Obstet Gynecol. 1996;7(4):245-50.

16. Souka AP, Snijders RJ, Novakov A, Soares W, Nicolaides KH. Defects and syndromes in chromosomally normal fetuses with increased nuchal translucency thickness at 10-14 weeks of gestation. Ultrasound Obstet Gynecol. 1998;1 1 (6):391-400.
17. Souka AP, Von Kaisenberg CS, Hyett JA, Sonek JD, Nicolaides $\mathrm{KH}$. Increased nuchal translucency with normal karyotype. Am J Obstet Gynecol. 2005;192(4):1005-21.

18. Nicolaides KH, Spencer K, Avgidou K, Faiola S, Falcon O. Multicenter study of first-trimester screening for trisomy 21 in 75,821 pregnancies: results and estimation of the potential impact of individual risk-orientated two stage first-trimester screening. Ultrasound Obstet Gynecol. 2005;25(3):221-6.

19. Down LJ. Observations on an ethnic classification of idiots. Clin Lect Rep Lond Hosp. 1866;3:259-62.

20. Cicero S, Curcio P, Papageorghiou A, Sonek J, Nicolaides K. Absence of nasal bone in fetuses with trisomy 21 at 11-14 weeks of gestation: an observational study. Lancet. 2001;358(9294):1665-7.

21. Cicero S, Spencer K, Avgidou K, Faiola S, Nicolaides KH. Maternal serum biochemistry at $11-13(+6)$ weeks in relation to the presence or absence of the fetal nasal bone on ultrasonography in chromosomally abnormal fetuses: an updated analysis of integrated ultrasound and biochemical screening. Prenat Diagn. 2005;25(1 1):977-83.

22. Cicero S, Avgidou K, Rembouskos G, Kagan KO, Nicolaides KH. Nasal bone in first-trimester screening for trisomy 21. Am J Obstet Gynecol. 2006;195(1):109-14.

23. Falcon O, Auer M, Gerovassili A, Spencer K, Nicolaides KH. Screening for trisomy 21 by fetal tricuspid regurgitation, nuchal translucency and maternal serum free beta-hCG and PAPP-A at $11+0$ to $13+$ 6 weeks. Ultrasound Obstet Gynecol. 2006;27(2):151-5.

24. Faiola $S$, Tsoi E, Huggon IC, Allan LD, Nicolaides KH. Likelihood ratio for trisomy 21 in fetus with tricuspid regurgitation at the 11 to 13 + 6 week scan. Ultrasound Obstet Gynecol. 2005;26(1):22-7.

25. Matias A, Gomes C, Flack N, Montenegro N, Nicolaides KH. Screening for chromosomal abnormalities at 10-14 weeks: the role of ductus venosus blood flow. Ultrasound Obstet Gynecol. 1998; 12(6):380-4.

26. Toyama JM, Brizot ML, Liao AW, Lopes LM, Nomura RM, Saldanha $\mathrm{FA}$, et al. Ductus venosus blood flow assessment at 11 to 14 weeks of gestation and fetal outcome. Ultrasound Obstet Gynecol. 2004;23(4):341-5.

27. Borrell A, Gonce A, Martinez JM, Borobio V, Fortuny A, Coll O, et al. First-trimester screening for Down syndrome with ductus venosus Doppler studies in addition to nuchal translucency and serum markers. Prenat Diagn. 2005;25(10):901-5.

28. Maiz N, Kagan KO, Milovanovic Z, Celik E, Nicolaides KH. Learning curve for Doppler assessment of ductus venosus flow at 11-13+6 weeks. Ultrasound Obstet Gynecol. In press 2008.

29. Cicero S, Curcio P, Rembouskos G, Sonek JD, Nicolaides KH. Maxillary length at 11-14 weeks of gestation in fetuses with trisomy 21. Ultrasound Obstet Gynecol. 2004;24(1):19-22.

30. Dagklis $T$, Borenstein $M$, Peralta $C F$, Faro $C$, Nicolaides $K H$. Three-dimensional evaluation of mid-facial hypoplasia in fetuses with trisomy 21 at $11+0$ to $13+6$ weeks. Ultrasound Obstet Gynecol. 2006;28(3):261-5.

31. Sonek J, Borenstein M, Dagklis T, Persico N, Nicolaides KH. Frontomaxillary facial angle in fetuses with trisomy 21 at 11-13(6) weeks. Am J Obstet Gynecol. 2007;196(3):271.e1-4.

32. Plasencia W, Dagklis T, Sotiriadis A, Borenstein M, Nicolaides KH. Frontomaxillary facial angle at $11+0$ to $13+6$ weeks' gestationreproducibility of measurements. Ultrasound Obstet Gynecol. 2007;29(1):18-21. 